\title{
Astrocytes as targets for Venezuelan equine encephalitis virus infection
}

\author{
Bruce A Schoneboom*,1, Marion J Fultz ${ }^{3}$, Thomas H Miller ${ }^{5}$, Leslie C McKinney ${ }^{4}$ and Franziska B Grieder ${ }^{1,2}$ \\ ${ }^{1}$ Program in Neuroscience, Uniformed Services University of the Health Sciences, Bethesda, MD, USA; ${ }^{2}$ Department of \\ Microbiology and Immunology, Uniformed Services University of the Health Sciences, Bethesda, MD, USA; ${ }^{3}$ Department \\ of Pathology, Uniformed Services University of the Health Sciences, Bethesda, MD, USA; ${ }^{4}$ Armed Forces Radiobiology \\ Research Institute, Bethesda, MD, USA; ${ }^{5}$ Walter Reed Army Medical Center, Washington, DC, USA
}

\begin{abstract}
Venezuelan equine encephalitis virus (VEE) produces an acute infection in humans and induces a well-characterized cytopathic effect in neurons of the central nervous system (CNS). However, little is known about the role of glial cells in response to VEE infection of the CNS. Our results demonstrate that VEE is capable of a productive infection in primary astrocyte cultures and that this infection is cytotoxic. Further, there were significant differences in the growth kinetics comparing virulent and attenuated strains of VEE. Additionally, VEE infection of astrocyte cultures induced gene expression of two neuro-immune modulators, tumor necrosis factor-alpha (TNF- $\alpha$ ) and inducible nitric oxide synthase (iNOS). Assays for TNF- $\alpha$ protein and nitric oxide (NO) demonstrated high levels of TNF- $\alpha$ protein and low levels of NO in response to VEE infection of astrocytes. These observations suggest an important role of astrocytes in this virus-induced encephalitis, and that interactions between astrocytes, other glial cells, and neurons may be important in VEE pathogenesis. Such interactions, which could impact neuronal survival, may include loss of functional changes in astrocytes or, alternatively, their production of neurotoxic molecules.
\end{abstract}

Keywords: alphavirus; encephalitis; glia; cytokines

\section{Introduction}

Glial cells play a central role in neuronal function and viability. Astrocytes, the predominant glial cell type in the central nervous system (CNS), outnumber neurons by a ratio of $8: 1$ and carry out critical functions in normal CNS physiology including neuronal guidance during development (Juliano et al, 1996), structural processes for the blood-brain barrier (Janzer and Raff, 1987), buffering of potassium ions, removal of neurotransmitters, specifically glutamate (Keyser and Pellmar, 1994; Marrero and Orkand, 1996; Orkland and Opava, 1994; Vernadakis, 1996), and synthesis of essential neurotrophic factors (Gray and Patel, 1992; Muller et al, 1984; Schmalenbach and Muller, 1993; Wilkin et al, 1990; Yoshida and Gage, 1991). Dysfunction of the CNS can result from trauma, hypoxia, toxic chemicals, radiation, neurodegenerative diseases

*Correspondence: BA Schoneboom

Received 30 December 1998; revised 5 March 1999; accepted 15 March 1999 such as Parkinson's or Alzheimer's diseases, and certain neurotropic infections including virus infections. Regardless of the type of insult, neuronal degeneration appears to be due to a final common pathway (Dugan and Choi, 1994) that includes glial cell activation or dysfunction (Mucke and Eddleston, 1993). This results in loss of trophic support, production of free radicals, or excitotoxicity.

Venezuelan equine encephalitis virus (VEE) is a positive-sense RNA virus indigenous to Central, South and parts of North America. A member of the Togaviridae family, this mosquito-transmitted virus causes encephalitis in horses, but is also capable of causing disease in humans. The most recent outbreak of the disease occurred in 1995 where over 12000 cases were reported in South America (MMWR, 1995). The characteristic clinical features of this infectious encephalitic disease include headache, fever, chills, skin rash and malaise. Clinical signs usually persist for 5-10 days, and encephalitis develops in approximately $0.4 \%$ of cases, however, children are particularly vulnerable as their occurrence of encephalitis is approximately 
4\% (de la Monte et al, 1985; Kissling and Chamberlain, 1967).

The pathogenesis of VEE has been described as a primary infection of lymphocytes and neurons (Grieder et al, 1995, 1997; Grieder and Nguyen, 1996; Jackson et al, 1991; Jackson and Rossiter, 1997; Johnson et al, 1997). While it has been established that neurons in the CNS undergo degeneration following VEE infection (Charles et al, 1995; Grieder et al, 1995; Jackson et al, 1991; Jackson and Rossiter, 1997), the role of glial cells during the acute stage of VEE infection is unclear. Astrocytes are targets for other viral infections including JC virus (Aksamit et al, 1986), Theiler's virus (Aubert et al, 1987), Visna virus (Stowring et al, 1985), Borna virus (Carbone et al, 1991), as well as Human Immunodeficiency virus type-1 (Tornatore et al, 1994). However, these viruses induce slow, progressive diseases of the CNS, which differ from VEE in that VEE causes an acute, rapidly progressing disease. Understanding the responses of astrocytes in an acute infection and how these responses differ from slowly progressing infections is necessary for understanding acute inflammatory responses in the CNS.

Recently, an understanding of the unique immune system of the CNS has emerged. Previously, the CNS was described as 'immunologically privileged', due to the isolation of the CNS from immune surveillance by circulating lymphocytes because of the blood-brain barrier, and the absence of a lymphatic drainage system. Recognizing these differences in CNS immune system structure and function, a relatively new area of research has developed to characterize how the CNS responds to infections and injury. It is now understood that glial cells, specifically astrocytes and microglia, play a critical role in orchestrating the immune response of the CNS. Besides their physiologic role in CNS homeostasis, astrocytes can function as antigen presenting cells in association with major histocompatibility complex class I and class II molecules on their surface (Mucke and Eddleston, 1993; Neumann et al, 1996; Nikcevich et al, 1997), secrete cytokines and growth factors (Benveniste, 1992; Brodie et al, 1997; Chung and Benveniste, 1990; Clatterbuck et al, 1996; Lieberman et al, 1989; Mendez et al, 1997), phagocytose debris (Bechmann and Nitsch, 1997), and produce reactive oxygen and nitrogen intermediates (Banati et al, 1993; Brodie et al, 1997; Chao et al, 1996).

Our experiments characterize VEE infection of astrocytes in vitro and describe VEE replication kinetics and VEE induction of astrocyte cell death. Experiments were also conducted to determine if astrocytes could respond to VEE infection by the upregulation of certain pro-inflammatory molecules at the level of gene transcription and translation. Specifically, tumor necrosis factor- $\alpha(\mathrm{TNF}-\alpha)$ and inducible nitric oxide synthase (iNOS) were assessed by means of reverse transcriptase polymerase chain reaction (RT-PCR) and Southern blot analysis because of the documented production of these two molecules in response to various stimuli including interferon-gamma (IFN $\gamma$ ) or lipopolysaccharide (LPS) (Lowenstein et al, 1993; Xie et al, 1993) and certain neurotropic viruses (Lieberman et $a l, 1989)$. Furthermore, TNF- $\alpha$ protein secretion into the culture supernatant, as well as nitrite $\left(\mathrm{NO}_{2}^{-}\right)$, the stable oxidation product of nitric oxide (NO), were assessed by quantitative assays. These experiments form the basis for understanding the role of glial cells in early neuro-immune responses against this acute viral infection and the potential impact on neurons of the CNS.

\section{Results}

Astrocytes are targets for VEE infection

Astrocyte cultures infected with VEE for $18 \mathrm{~h}$ revealed a consistent pattern of morphological changes characteristic of apoptosis. Specifically, nuclei became concentric and fragmented, however no specific immunostaining for VEE could be visualized on the cell surface or in the cytoplasm (Figure 1B). At $24 \mathrm{~h}$ post-infection (p.i.), positive immunostaining for VEE antigen accompanied by early signs of cytolysis was evident (Figure 1C), and at $48 \mathrm{~h}$ positive immunostaining was most intense with severe cytopathic effects (CPE) of the monolayer (Figure 1D). In contrast, mock-infected control wells demonstrated healthy cell populations with defined centrally located nuclei and normal cell morphology throughout the experimental time course (Figure 1A).

\section{Astrocytes support VEE replication}

Primary astrocytes were infected with two molecularly cloned strains of VEE with different pathogenesis, a virulent strain (V3000) and an attenuated strain (V3010), to determine if astrocytes could support VEE replication and if the in vivo phenotype influenced replication in culture. Following VEE entry and removal of non-penetrated virus at $1 \mathrm{~h}$ p.i., both strains replicated rapidly in astrocytes with a peak of released virus at $24 \mathrm{~h}$ p.i. (Figure 2). However, the attenuated strain V3010 demonstrated slower replication rates as compared to the virulent V3000 and this difference was statistically different at $6 \mathrm{~h}$ p.i. $\left({ }^{*} P<0.05\right)$. These data suggest that replication rates in astrocytes may contribute to the in vivo phenotype of VEE.

All extracellular VEE titers remained stable for the initial $48 \mathrm{~h}$ p.i. and then began to decline. This decline in VEE titers coincided with the microscopically observed CPE in VEE infected astrocytes (e.g., cytoplasmic granulation, cell shrinking and rounding) including the appearance of floating cellular debris in the culture supernatant. The slow 

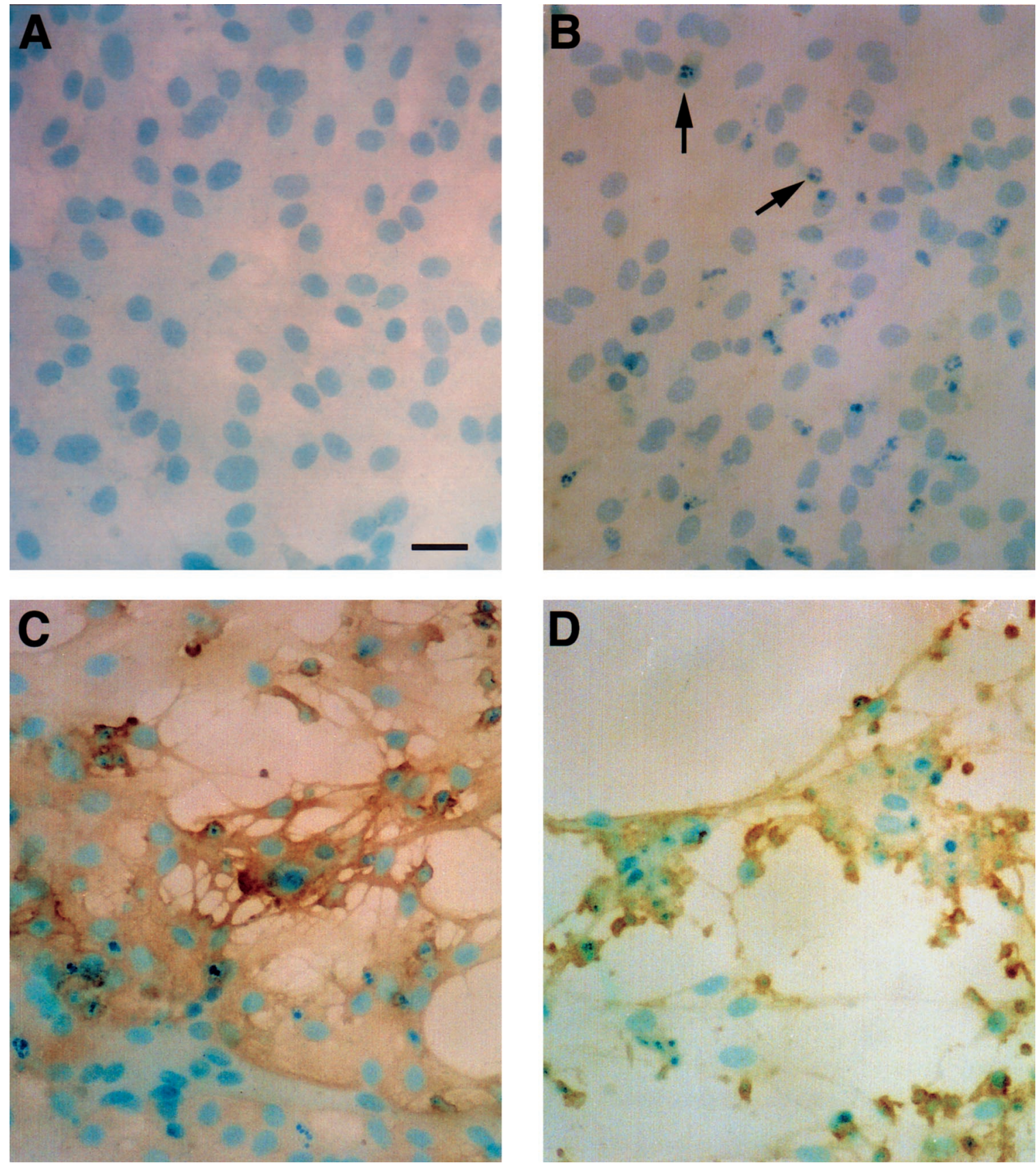

Figure 1 Photomicrograph of immunoperoxidase staining of astrocytes infected with VEE or mock-infected. Mock-infected controls show no staining (A). Early time points post-VEE infection $(\mathbf{B}, 18 \mathrm{~h})$ demonstrate morphologic changes in astrocyte cultures including nuclear condensation and fragmentation (arrows), but no positive staining for VEE. Time points 24 and $48 \mathrm{~h}$ (C and D, respectively) reveal positive brown staining for VEE and cytopathic effects to primary astrocyte cultures. Scale bar=10 $\mu \mathrm{m}$.

decrease in VEE titers in primary astrocyte culture supernatants (1.2 logs over $48 \mathrm{~h}$ ) reflects the relative stability of this virus in non-cell-associated, fluid phase at $37^{\circ} \mathrm{C}$.

\section{Cytopathic effects of VEE infection}

Although early morphologic changes were evident at $18 \mathrm{~h}$ p.i. (Figure 1B) there was not a decline in cell viability until $24 \mathrm{~h}$ p.i. (Figure 3 ). This appearance of CPE occurs at the same time as peak virus titers measured in the supernatant. While both VEE strains produced $\mathrm{CPE}$ in astrocytes, the attenuated strains resulted in delayed cytopathology. This trend of delayed CPE was not statistically significant. Despite similar peak virus titers and cytopathol- 
ogy at $72 \mathrm{~h}$ p.i., differences in kinetics in replication and $\mathrm{CPE}$ in astrocytes may correlate with the in vivo phenotypes of the different VEE strains.

Induction of pro-inflammatory genes in astrocytes following VEE infection

Because of kinetic differences in replication rates for VEE and CPE in astrocytes we evaluated kinetics in gene induction for two pro-inflammatory molecules following infection with the molecularly cloned VEE strains V3000 and V3010. IFN $\gamma /$ LPS treatment was used as a positive control. Both VEE strains (virulent V3000 and neuro-attenuated V3010) induced iNOS and TNF- $\alpha$ genes in astrocyte cultures in response to infection (Figure 4).

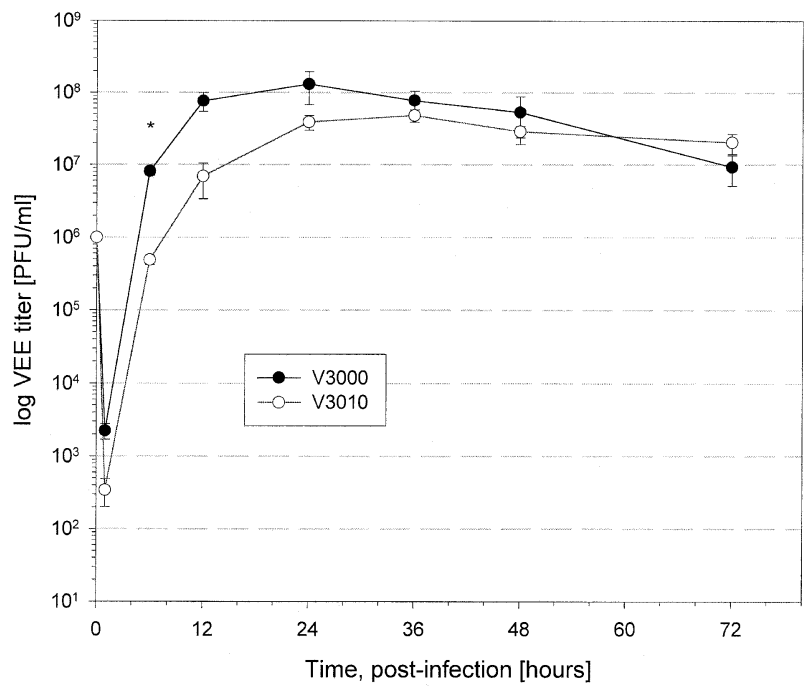

Figure 2 Astrocyte cultures were infected at an MOI of 1.0, and VEE titers in the culture supernatant were determined at 1, 6, 12, 24, 36, 48 and $72 \mathrm{~h}$ p.i. Virulent and attenuated VEE strains demonstrate rapid, logarithmic growth within the first $24 \mathrm{~h}$. Attenuated V3010 demonstrated a statistically significant slower rate of replication at $6 \mathrm{~h}$ p.i. $\left({ }^{*} P<0.05\right)$ as compared to virulent V3000.
Statistical analyses of triplicate samples indicated that IFN $\gamma /$ LPS-stimulated astrocytes had statistically significant increases in iNOS gene expression as early as $6 \mathrm{~h}$ p.i. as compared to uninfected controls $\left({ }^{*} P<0.05\right)$, whereas both virus-treated groups were not statistically significant from controls until $12 \mathrm{~h}$ p.i. (Figure 5). These levels of iNOS gene induction peaked at $24 \mathrm{~h}$ p.i. and remained higher throughout the remainder of the experiment for all three groups as compared to uninfected controls.

Comparisons among groups indicated that the IFN $\gamma /$ LPS-stimulated astrocytes upregulated gene expression for TNF- $\alpha$ as early as $2 \mathrm{~h}$ post-stimulation and then declined, whereas the virus-infected astrocytes showed slower upregulation of TNF- $\alpha$

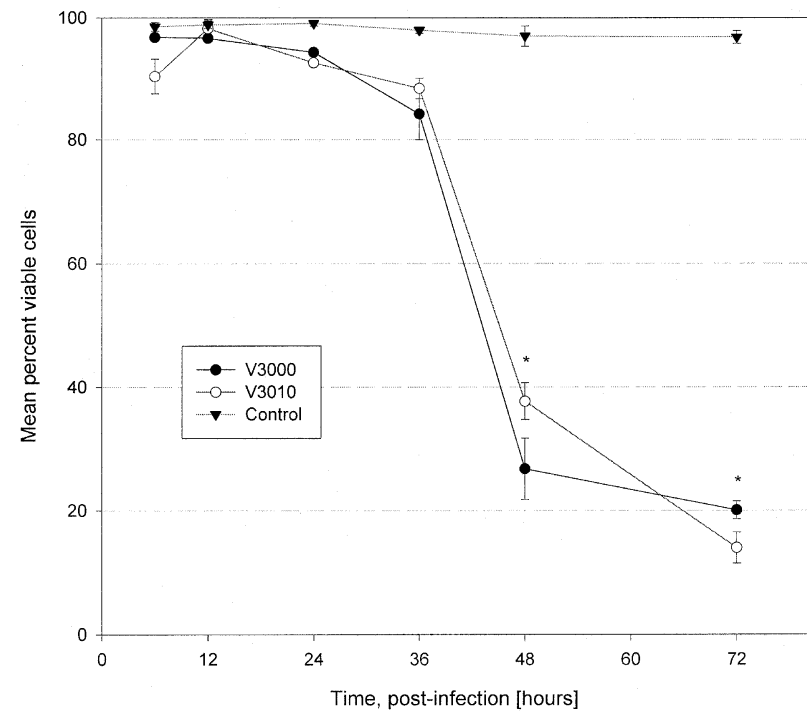

Figure 3 Astrocyte cultures were infected at an MOI of 1.0 with virulent and attenuated VEE strains and cell viability was determined by Trypan Blue exclusion test. Mean per cent \pm s.e.m. of viable cells was determined by three independent samplings along with mock controls for each time point. Both VEE strains were cytopathic for astrocytes $\left({ }^{*} P<0.05\right)$ as compared to uninfected controls.

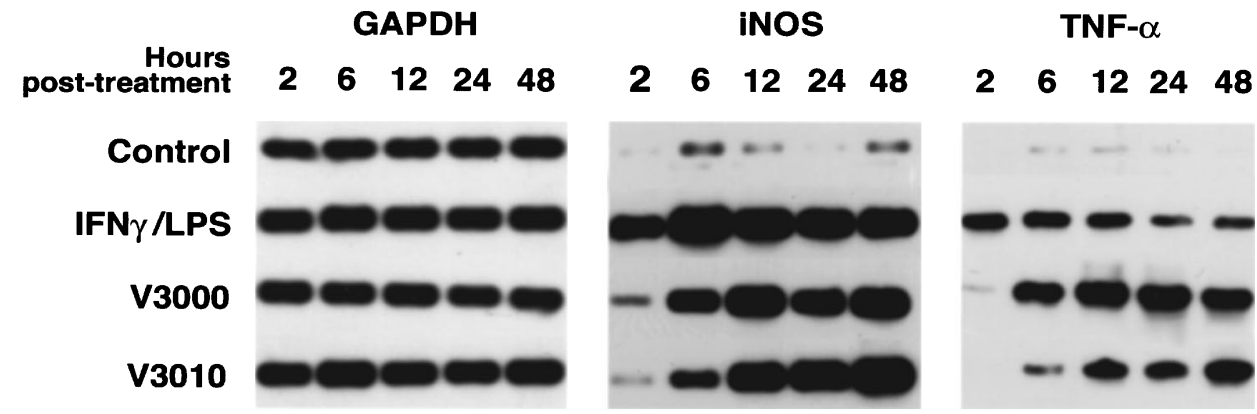

Figure 4 Southern blots for gene expression of GAPDH, iNOS, and TNF- $\alpha$. Astrocytes were infected with virulent V3000 or neuroinvasive, attenuated clone V3010 at an MOI of 1.0. Both strains of VEE demonstrate gene induction as early as $6 \mathrm{~h}$ p.i. The housekeeping gene GAPDH remains unchanged throughout the experiment. 
message RNA (Figure 6). This upregulation for TNF- $\alpha$ gene expression was statistically significant for V3000 as early as $6 \mathrm{~h}$ p.i. as compared to uninfected controls $\left({ }^{*} P<0.05\right)$. These levels of TNF- $\alpha$ gene induction remained higher throughout the experiment for both virus-infected groups as compared to uninfected controls. Similar to results previously described by others (Chung and Benveniste, 1990), our experiments demonstrated that a combination of IFN $\gamma$ and LPS had a synergistic effect on gene expression in astrocytes when compared to individual stimulatory effects by IFN $\gamma$ or LPS (data not shown). Finally, our data demonstrate that astrocyte infection with VEE induced consistent levels of TNF- $\alpha$ gene expression when compared to IFN $\gamma /$ LPS and that levels of TNF- $\alpha$ gene expression were highest for the virulent V3000.

\section{Production of $N O$ and $T N F-\alpha$ in astroyctes in} response to VEE infection

Nitrite assays of culture supernatants from primary astrocytes infected with VEE or stimulated with IFN $\gamma /$ LPS demonstrated that nitric oxide was produced at statistically significant levels $\left({ }^{*} P<0.05\right.$, Figure 7$)$ as compared to uninfected controls. Nitrite levels in identical astrocyte cultures infected with either the virulent or the neuroattenuated VEE clone remained at base line for the first $24 \mathrm{~h}$ p.i. and were only elevated at low levels $(5-6 \mu \mathrm{M} / \mathrm{ml})$ at $48 \mathrm{~h}$ p.i. These low levels of nitrite in VEE-infected astrocytes were statistically significant as compared to uninfected controls $\left({ }^{*} P<0.05\right)$. Interestingly, there was no difference in NO production between the virulent and attenuated VEE-infected astrocytes. In contrast, the NO production in the positive control treated

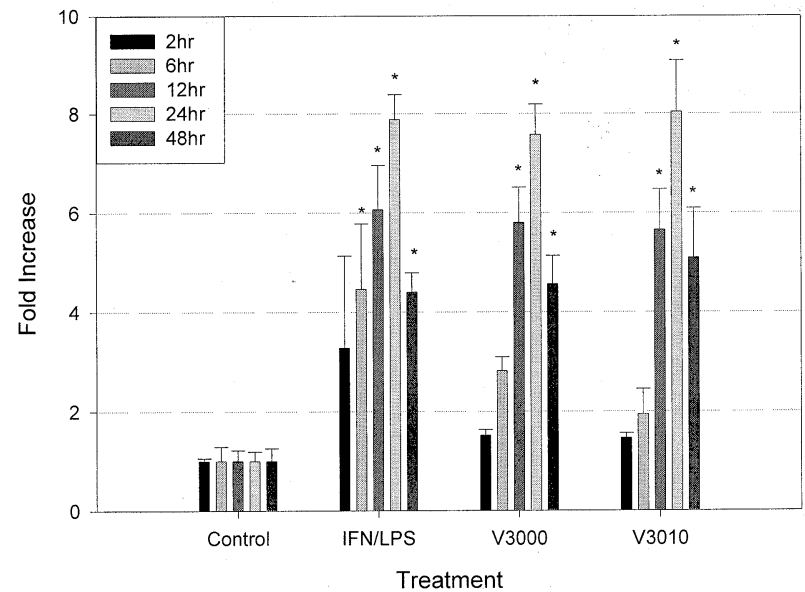

Figure 5 Histogram depicting changes in gene expression for iNOS based on optical density measurements in response to VEE infection. Bars represent fold increase as compared to untreated controls (means \pm s.e.m.) of three independent samples. Both virulent and attenuated strains for VEE, as well as IFN $\gamma / \mathrm{LPS}$, were capable of significant induction for iNOS $\left({ }^{*} P<0.05\right)$. astrocyte cultures (IFN $\gamma / \mathrm{LPS}$ ) resulted in elevated nitrite levels as early as $12 \mathrm{~h}$ post-stimulation $\left({ }^{*} P<0.05\right)$ and nitrite levels continuously increased over the experimental time course.

Immunoassays of these culture supernatants demonstrated that these cells secreted significant amounts of TNF- $\alpha$ when compared to untreated controls $\left({ }^{*} P<0.05\right.$, Figure 8$)$. Infection of identical astrocyte cultures with virulent V3000 resulted in

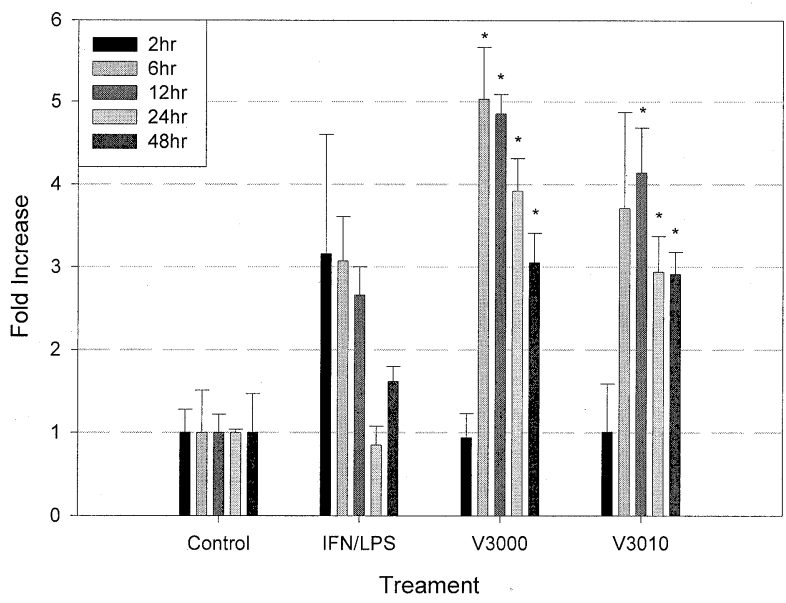

Figure 6 Histogram (mean \pm s.e.m. of three independent samples) depicting changes in gene expression for TNF- $\alpha$ based in optical density measurements in response to VEE infection. Virulent and attenuated VEE significantly induced TNF- $\alpha$ gene expression in primary astrocytes $\left({ }^{*} P<0.05\right)$ as compared to uninfected controls. Virulent V3000 upregulated TNF- $\alpha$ gene expression as early as $6 \mathrm{~h}$ p.i., and levels of TNF- $\alpha$ gene expression in both virus genotypes were higher as compared to IFN $\gamma /$ LPS stimulated astrocytes.

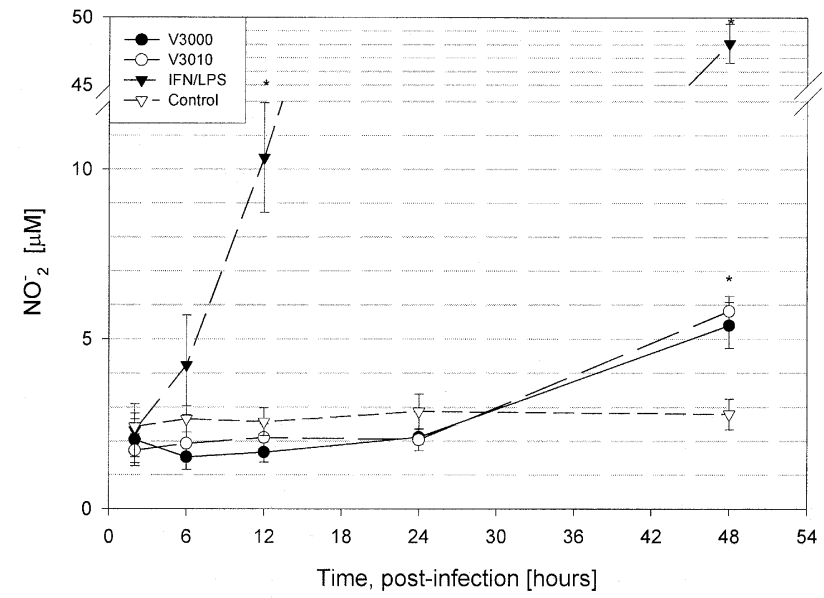

Figure 7 Astrocytes infected with virulent V3000 or neuroattenuated V3010 or stimulated with IFN $\gamma / \mathrm{LPS}$ showed very different kinetics and levels of nitric oxide production. IFN $\gamma / \mathrm{LPS}$ stimulated astrocytes produced high levels of nitrite that resulted in final concentrations of $48 \mu \mathrm{M}$ nitrite at $48 \mathrm{~h}$, whereas VEEinfected astrocytes produced low levels of nitrite $(5 \mu \mathrm{M})$ that were only detectable at $48 \mathrm{~h}$ p.i. $\left({ }^{*} P<0.05\right.$ when compared to uninfected controls). 


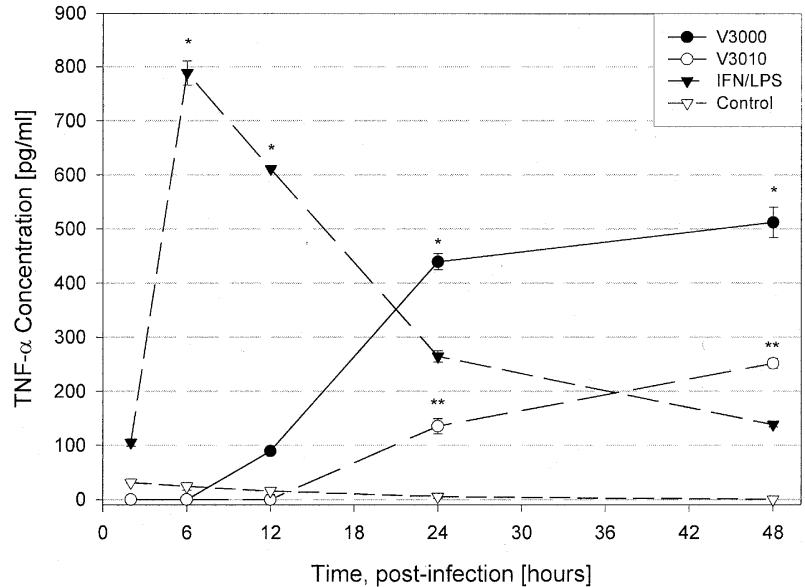

Figure 8 Astrocyte supernatants were analzyed for TNF- $\alpha$ protein levels following infection with virulent V3000 or neuro-attenuated $\mathrm{V} 3010$ or stimulated with IFN $\gamma / \mathrm{LPS}$. IFN $\gamma /$ LPS-stimulated astrocyte production of TNF- $\alpha$ peaked at $6 \mathrm{~h}$ post-stimulation $\left({ }^{*} P<0.05\right)$ and then declined to near baseline levels by $48 \mathrm{~h}$. VEE-infected astrocyte production of TNF- $\alpha$ peaked at $48 \mathrm{~h}$ p.i. ( $\left.{ }^{*} P<0.05\right)$. Neuro-attenuated V3010 infection of astrocytes resulted in significantly lower levels of TNF- $\alpha$ as compared to virulent V3000 at 24 and $48 \mathrm{~h}$ p.i. $\left({ }^{*} P<0.05\right)$.

secreted TNF- $\alpha$ levels of $500 \mathrm{pg} / \mathrm{ml}$, but this peak was not reached until $48 \mathrm{~h}$ p.i. Infection with the neuro-attenuated V3010 resulted in similar TNF- $\alpha$ secretion kinetics, however the levels of TNF- $\alpha$ measured in the supernatants were significantly reduced as compared to V3000 $\left({ }^{*} P<0.05\right)$. Primary astrocyte cultures stimulated with IFN $\gamma / \mathrm{LPS}$ were used as positive controls and secreted $800 \mathrm{pg} /$ $\mathrm{ml}$ of TNF- $\alpha$ as early as $6 \mathrm{~h}$ post-stimulation $\left({ }^{*} P<0.05\right)$. This peak sharply declined over the next $24 \mathrm{~h}$ and returned to near baseline levels by $48 \mathrm{~h}$ post-stimulation.

\section{Discussion}

VEE is capable of infecting primary astrocytes and replicating efficiently, with the consequences of causing substantial cell death. It is well documented that VEE is neuro-virulent (Charles et al, 1995; Grieder et al, 1995; Jackson et al, 1991; Jackson and Rossiter, 1997), however, our in vitro experiments, as well as in vivo experiments from Jackson and Rossiter (1997), suggest that astrocytes are a potential target for VEE after it has established a productive infection in the CNS. If substantial numbers of astrocytes undergo cell death following VEE infection in vivo, these astrocyte-VEE interactions could be a contributing factor to neurodegeneration because essential astrocyte functions are lost. Alternatively, if during the course of VEE infection astrocytes are activated to produce proinflammatory cytokines and other diffusible mole- cular immuno-modulators, this response may be detrimental to neighboring neurons.

Pro-inflammatory responses have been associated with acute neurodegeneration in several different models, including traumatic brain injury and ischemia (Rothwell and Strijbos, 1995) and systemic bacterial infections (Waage et al, 1989). Further, inflammatory responses in the CNS have also been linked to specific types of neurological disease, such as autoimmune processes in multiple sclerosis (Benveniste, 1992), AIDS dementia (Adamson et al, 1996; Talley et al, 1995; Yoshioka et al, 1995), or other CNS viral infections (Lieberman et al, 1989). Astrocytes and other glial cells during the inflammatory response in the CNS may influence the balance between host protection and neurotoxicity.

Neuro-immune responses of astrocytes to infection by two phenotypically different VEE strains demonstrate that the expression of two pro-inflammatory genes, iNOS and TNF- $\alpha$, are induced when compared to uninfected control cultures. These two VEE strains, the molecularly cloned virulent V3000 and the neuro-invasive, but attenuated clone, V3010, differ in their genotype by one single nucleotide (Davis et al, 1991). These two molecularly cloned VEE strains with only a single amino acid difference that results in extremely different in vivo phenotypes allow us to elucidate cellular responses to infection including cytotoxicity and gene induction in a variety of potential target cell populations. Our finding of slower replication rates in astrocytes for V3010 supports previous findings that slower viral replication rates of V3010 in the periphery may play a role in the attenuated phenotype (Grieder et al, 1995).

In previous work, investigating pro-inflammatory gene induction in the periphery in response to VEE infection, we demonstrated that two molecularly cloned VEE strains elicited different cytokine responses when compared to one another. Specifically, an attenuated strain resulted in slower induction kinetics, suggesting that a delayed cytokine response may influence the development of host-protection (Grieder et al, 1997). In contrast, the present results indicated that two neuro-invasive VEE clones are capable of strongly inducing two important genes in astrocytes, and that the kinetics of gene expression are similar. These similarities in iNOS and TNF- $\alpha$ gene expression following virulent and attenuated VEE infection in vitro, yet very different mortality rates following infection with different VEE phenotypes in vivo suggest that other factors are involved in the CNS pathogenesis. In the present study, immunoassays for TNF- $\alpha$ demonstrate that additional regulatory mechanisms, such as posttranscriptional events or protein function regulation are important in the final outcome of TNF- $\alpha$ secretion into the supernatant. Further support for 
post-transcriptional regulation is the observation of low nitrite levels in VEE-infected astrocyte cultures. Levels of nitrite were much lower than predicted given the quantitation of iNOS gene expression in virus-infected and IFN $\gamma / \mathrm{LPS}$-induced control astrocytes. Possible explanations for post-transcriptional regulation of iNOS include the availability of substrates and cofactors essential for the synthesis of iNOS and NO, or other unknown regulatory factors. Such post-transcriptional regulation of iNOS has been demonstrated in other immunocompetent cells (Le Page et al, 1996). These observations support the concept that the final outcome of CNS infection with VEE of different phenotypes may not only depend upon differences in virus replication rates and dissemination, but also upon other cell targets such as astrocytes or microglia, and the induction of pro-inflammatory genes at the level of expression or post-transcriptional regulation.

Other investigators have determined pro-inflammatory responses in the brain following infections with closely related viruses. Griffin and colleagues in 1994 characterized cytokine expression in the brain in response to the alphavirus Sindbis virus (SB) (Tucker et al, 1996; Wesselingh et al, 1994). Their results demonstrated that pro-inflammatory cytokines play a significant role in the pathogenesis of SB-induced encephalitis and, specifically, that NO may be involved in protecting mice from fatal progression of the disease. Sindbis virus has also been utilized to characterize cytokine responses in murine astrocytes in vitro (Brodie et al, 1997). In contrast to the SB in vivo studies, these investigators found that neuro-virulent SB infection in astrocytes induced TNF- $\alpha$ expression, but not iNOS, and the authors concluded that SB infection of astrocytes does not produce enough TNF- $\alpha$ to induce iNOS gene expression. Differences between our findings with VEE and SB infection of astrocytes may include host species differences, differences between molecularly cloned VEE and biological mutants of SB, and difference in the sensitivity of quantitative methods (i.e. semi-quantitative PCR for VEE versus Western blots for SB).

Studies investigating Japanese encephalitis virus (JEV), a closely related virus in the family Flaviviridae, supports the beneficial role of NO in viral encephalitis (Lin et al, 1997) both in vivo and in vitro. In vitro, inhibition of replication of JEV in IFN $\gamma$-activated murine macrophages was correlated to cellular NO production. In vivo, the mortality rate increased as the JEV-infected mice were administered a NOS competitive inhibitor. However, these results with JEV are in contrast to results describing experiments involving another Flavivirus, Tickborne encephalitis virus (TBE) (Kreil and Eibl, 1996). Macrophages from TBE-infected mice spontaneously produced NO in vitro and high levels of NO production did not display an inhibitory influence on TBE replication. In vivo administration of a competitive inhibitor of NO production to TBEinfected mice significantly increased their mean survival time. These data suggest that NO plays a role in the development of TBE disease and that inhibition of NO formation may be beneficial to the host. These contrasting findings suggest that inducible genes, specifically iNOS, in the CNS have unique responses to similar types of challenges and that there is a low threshold from host protection to toxicity. Further analysis with sensitive quantitative and qualitative methods is necessary to unravel the role of iNOS and NO production, as well as other pro-inflammatory mediators, following viral infections of the CNS.

Primary astrocyte cultures are an important tool in understanding the relationship between glial cells, neurotropic viruses, and cytokines or other diffusable molecules. These highly homogenous cultures are useful in isolating responses that may occur during the neurotropic phase of VEE infection in vivo. The benefits of using astrocyte cultures as an experimental model for studying CNS viral infections include characterizing replication rates, determining cellular outcomes and neuro-immune responses. Similar models have been used for other neurotropic viruses including Japanese encephalitis virus (Lin et al, 1997; Suri and Banerjee, 1995), Sindbis virus (Brodie et al, 1997), Tick-borne encephalitis virus (Kreil and Eibl, 1996), and the paramyxovirus Newcastle disease virus (Fisher et al, 1994; Lieberman et al, 1989, 1990; Rus et al, 1992). Moreover, astrocyte cultures have been used to characterize astrocyte responses to specific stimuli aimed at the upregulation of certain molecular factors including NO and TNF- $\alpha$. Such inducers of NO and TNF- $\alpha$ in astrocytes include IFN $\gamma$, LPS, as well as neurotropic viruses such as Newcastle disease virus and Theiler virus (Chung and Benveniste, 1990; Feinstein et al, 1996; Galea et al, 1994; MolinaHolgado et al, 1997; Rus et al, 1992). Combining primary glial cultures and molecularly cloned VEE with well-characterized phenotypes will help further this progress.

In summary, our results demonstrate that VEE infects astrocytes in vitro and that the response of these primary astrocytes to VEE infection includes cytotoxic effects and the induction of pro-inflammatory genes. Because of these findings in vitro and the fact that VEE is neuro-invasive, astrocytes are likely targets for infection after VEE has crossed the blood-brain barrier. Even if only a small subset of astrocytes are infected, because of the efficient replication rates, infected astrocytes may play a significant role in terms of increasing intracerebral viral titers and inducing specific neuro-immune mediators. Astrocyte infection and activation could therefore contribute to the pathogenesis of VEE encephalitis. Understanding the relationship of 
early neuro-inflammatory responses to VEE infection may help in targeting and manipulation of such responses that are beneficial. Such strategies could have significant application for a variety of neurodegenerative processes that share similar pathways, responses and outcomes.

\section{Materials and methods}

\section{Virus}

Two molecularly cloned VEE, virulent V3000 and attenuated V3010, were used (Davis et al, 1991; Grieder et al, 1995). The virulent V3000 and neuroinvasive, attenuated clone, V3010 differ in their genotype by one single nucleotide resulting in a single amino acid change at glycoprotein E2 position 76 . This nucleotide mutation replaces a glutamic acid in V3000 for lysine in V3010. Virulent V3000 is $100 \%$ fatal in mice regardless of route of injection. Attenuated V3010 is nonlethal when injected peripherally, and only has a $20 \%$ mortality rate when injected intracerebrally (Grieder et al, 1995). Molecularly cloned virus stocks were stored at $-80^{\circ} \mathrm{C}$ and all experiments were conducted in a biosafety level 3 laboratory.

\section{Primary astrocyte cultures}

Primary astrocyte cultures were established as previously described (McCarthy and de Vellis, 1980). Briefly, cerebrums were removed from 2day-old Sprague-Dawley rats using sterile technique. Meninges were stripped by microscopic dissection and cerebral hemispheres were dissociated by suction pipetting followed by centrifugation at 1000 r.p.m for $10 \mathrm{~min}$. The supernatant was removed and the cell pellet was resuspended in cell culture media. This suspension was then triturated sequentially through 18 gauge and 22 gauge needles, and cells were plated in Dulbecco's minimum essential media (DMEM) supplemented with $10 \%$ non-heat inactivated fetal bovine serum (FBS), 1\% L-glutamine, and $25 \mu \mathrm{g} / \mathrm{ml}$ gentamycin. After the establishment of a confluent monolayer (between 10-14 days), adherent microglia were removed by rotary shaker. The resulting cultures were characterized as astrocytes by positive immunofluorescent staining for glial fibrillary acidic protein (GFAP; Sigma, St. Louis, MO, USA), an intermediate filament which is expressed by astrocytes. The homogeneity of these astrocytes was determined by immunostaining identical cultures with a microglia specific cell-surface marker antibody OX42 (Serotec/Harlan; Indianapolis, IN, USA) and an oligodendrocyte specific antibody antiGal-C (Boehringer, Germany). The astrocyte primary cell cultures were determined to be greater than $95 \%$ homogenous by three independent samplings of GFAP stained cell cultures, and comparing those cell counts to phase contrast light microscopy. Contaminating micro- glia and oligodendrocytes were observed only on rare occasions.

\section{Immunoperoxidase staining of VEE-infected astrocytes}

Astrocyte cultures were passaged one time and plated into 16-well tissue culture chambers (Nunc Inc., Naperville, IL, USA) and incubated for $48 \mathrm{~h}$ at $37^{\circ} \mathrm{C}, 5 \% \mathrm{CO}_{2}$. Cell counts at this time were determined to be $1.5 \times 10^{5}$ cells per well. Monolayers were infected with VEE at a multiplicity of infection (MOI) of 1.0. Mock controls were inoculated with phosphate buffered saline (PBS) only. Following 1, 6, 12, 18, 24, or $48 \mathrm{~h}$ infection the cells were fixed in an ice cold 1:1 mixture of methanol and acetone for $5 \mathrm{~min}$ and allowed to air dry. Slides were treated with a 1:400 dilution of polyclonal rabbit anti-VEE serum (kindly provided by Drs George Ludwig and Jonathan Smith, USAMRIID, Ft. Detrick, MD, USA) and stained using an avidinbiotin-conjugated peroxidase staining kit (Vectastain ABC Kit, Burlingame, CA, USA) with diaminobenzidine (DAB) used as the chromagen resulting in brown staining (Grieder and Nguyen, 1996). Cells were double-stained with methylene blue to visualize nuclear structures. Controls for non-specific staining included stained mock-infected cells and infected cells treated with unimmunized rabbit serum incubated at the same dilution as the antiVEE rabbit serum.

\section{Virus growth kinetics}

Astrocytes were passaged one time and plated into $60 \mathrm{~mm}$ cell culture plates (Corning, NY, USA). Cultures were incubated for 5 days at $37^{\circ} \mathrm{C}, 5 \% \mathrm{CO}_{2}$ until $90 \%$ confluent. Cell counts at this time were determined to be $1.5 \times 10^{6}$ per $60-\mathrm{mm}$ cell culture plate. Triplicate astrocyte cell cultures were then infected with virulent V3000 or the attenuated V3010 virus at an MOI of 1.0 and incubated for $1 \mathrm{~h}$ at $37^{\circ} \mathrm{C}, 5 \% \mathrm{CO}_{2}$. Astrocytes were washed three times with PBS containing $0.1 \%$ donor calf serum (DCS) and $3 \mathrm{ml}$ of media was replaced. The initial samples were collected at this time, and subsequently at $6,12,24,36,48$, and $72 \mathrm{~h}$ p.i. Supernatant samples containing virus were immediately frozen at $-80^{\circ} \mathrm{C}$. Virus titers were determined as previously described by plaque assays on BHK-21 cells (American Type Culture Collection, Rockville, MD, USA) (Grieder and Nguyen, 1996; Scherer et al, 1971). Virus titers were calculated as plaque forming units (PFUs) per ml of supernatant.

\section{Astrocyte viability}

Astrocytes were passaged one time, plated into 6well culture plates (Corning, NY, USA) and incubated at $37^{\circ} \mathrm{C}, 5 \% \mathrm{CO}_{2}$ for 4 days. Cell counts were determined to be $3 \times 10^{5}$ cells per well. Medium was removed and three independent wells 
of astrocytes were infected with V3000 or V3010 virus at an MOI of 1.0 and incubated at $37^{\circ} \mathrm{C}, 5 \%$ $\mathrm{CO}_{2}$ for $1 \mathrm{~h}$. Mock-infected controls were treated with PBS only for $1 \mathrm{~h}$. Infected and control astrocytes were harvested at $6,12,24,36,48$, and $72 \mathrm{~h}$ p.i. Briefly, the astrocyte medium was removed and the monolayers were trypsinized. Trypsin action was neutralized with warm astrocyte medium containing 10\% FBS and triturated to lift the monolayer. Cells were stained with Trypan Blue (Life Technologies, Inc., Grand Island, NY, USA), counted by hemocytometer, and mean percentage ( \pm s.e.m.) of living cells calculated.

\section{Extraction of astrocyte mRNA}

Astrocytes were passaged one time and plated into 6 -well cultures plates and incubated at $37^{\circ} \mathrm{C}, 5 \%$ $\mathrm{CO}_{2}$ for 2 days. Cell counts were determined to be $1 \times 10^{6}$ cells per well. Medium was removed and wells were assigned to one of the following groups: (1) uninfected PBS control; (2) a combination of recombinant rat IFN $\gamma(100 \mathrm{U} / \mathrm{ml}$; Genzyme Corp, Cambridge, MA, USA) and LPS stimulated ( $1 \mu \mathrm{g} / \mathrm{ml}$ equals $200 \mathrm{U} / \mathrm{ml}$; protein free E. coli K235 LPS extracted by the method of McIntire et al (1967) kindly provided by Dr Stefanie Vogel, USUHS, Bethesda, MD, USA); and (3) infected with V3000 or V3010 at an MOI of 1.0 and incubated for $1 \mathrm{~h}$. Total cellular RNA was harvested from three independent samples per treatment group at 2, 6, 12, 24, and $48 \mathrm{~h}$ p.i. using RNAzol ${ }^{\mathrm{TM}} \mathrm{B}$ (Tel-Test, Inc., Friendswood, TX, USA) as previously described (Chomczynski and Sacchi, 1987). RNA was extracted with chloroform (Sigma, St. Louis, MO, USA), precipitated with isopropanol (Sigma, St. Louis, MO, USA) and diluted in diethylepyrocarbonate (DEPC)-treated water (Quality Biologicals, Inc., Gaithersburg, MD,
USA). The concentration of RNA in each sample was determined using a spectrophotometer (Beckman Instruments, Inc., Columbia, MD, USA). Specimens were stored at $-80^{\circ} \mathrm{C}$ until processing by RT - PCR.

\section{$R T-P C R$ detection of $m R N A$}

cDNA synthesis was performed by reverse transcription in a reaction volume of $25 \mu \mathrm{l}$ using: (1) $1 \mu \mathrm{g}$ of RNA; (2) random hexamer oligonucleotides at a concentration of $0.5 \mathrm{U}$; (3) $0.25 \mathrm{mM}$ mix of all four deoxynucleotide triphosphates (dNTPs); (4) $1 \times$ reverse transcriptase buffer $(50 \mathrm{mM}$ Tris-HCL, $\mathrm{pH}$ 8.3, $75 \mathrm{mM} \mathrm{KCL}, 3 \mathrm{mM} \mathrm{MgCl}_{2}$ ); $8 \mathrm{mM}$ DTT; and 200 U Moloney Murine Leukemia virus (MMLV) reverse transcriptase (GIBCO, Gaithersburg, MD, USA). The reaction mixture was incubated at $37^{\circ} \mathrm{C}$ for $60 \mathrm{~min}$, heated to $90^{\circ} \mathrm{C}$ for $5 \mathrm{~min}$ to denature the enzyme and cooled on ice before storage at $-20^{\circ} \mathrm{C}$. The final reaction volume was diluted with an addition $175 \mu \mathrm{l}$ of DEPC treated water.

Amplification of cDNA was accomplished using gene-specific sense and antisense oligonucleotide primers for rat glyceraldehyde-3-phosphate dehydrogenase (GAPDH), TNF- $\alpha$, and iNOS (Table 1). Products amplified from cDNA could be distinguished from genomic DNA because the primers were designed to span at least one intron. To each PCR reaction the following components were added: (1) $1.0 \mathrm{mM}$ dNTP mix; (2) $1 \times$ PCR buffer (50 mM KCL, $10 \mathrm{mM}$ Tris-HCL, $3 \mathrm{mM} \mathrm{MgCl}_{2}$ ); (3) $10 \mu \mathrm{l}$ of cDNA; (4) $0.2 \mu \mathrm{M}$ sense and antisense primers; (5) and $1 \mathrm{U}$ Taq polymerase (Promega, Madison, WI, USA). PCR reaction mixture was then amplified using an automated PCR thermocycler (Perkin-Elmer, Norwalk, CT, USA). Ten $\mu \mathrm{l}$ of amplified PCR products along with $2 \mu \mathrm{l}$ of gel

Table 1 Oligonucleotides specific for rat used in PCR and Southern blots

\begin{tabular}{|c|c|c|c|}
\hline Product & Primer/probe & Sequence ( $5^{\prime}$ to $3^{\prime}$ direction) & Product size \\
\hline GAPDH & $\begin{array}{l}\text { sense } \\
\text { antisense } \\
\text { probe }\end{array}$ & $\begin{array}{l}\text { CCATGGAGAAGGCTGGGG } \\
\text { CAAAGTTGTCATGGATGACC }^{\text {CTAAGCATGTGGTGGTGCA }}{ }^{1}\end{array}$ & $195 \mathrm{bp}$ \\
\hline $\mathrm{TNF}-\alpha$ & $\begin{array}{l}\text { sense } \\
\text { antisense } \\
\text { probe }\end{array}$ & $\begin{array}{l}\text { AGAACTCCAGGCGGTGTCTGT } \\
\text { CCTTGTCCCTTGAAGAGAACC } \\
\text { ATCAGTTCCATGGCCCAGA }\end{array}$ & $365 \mathrm{bp}$ \\
\hline iNOS & $\begin{array}{l}\text { sense } \\
\text { antisense } \\
\text { probe }\end{array}$ & $\begin{array}{l}\text { CTGCATGGAACAGTATAAGGCAAAC } \\
\text { GAGACAGTTTCTGGTCGATGTCATGA } \\
\text { GGGCTCCAGCATGTACC }\end{array}$ & $229 \mathrm{bp}$ \\
\hline
\end{tabular}

PCR amplification specifications

Product Cycle number Annealing temperature Accession number Reference

\begin{tabular}{|c|c|c|c|c|}
\hline GAPDH & 30 & $55^{\circ} \mathrm{C}$ & M17701 & (Tso et al, 1985) \\
\hline TNF- $\alpha$ & 28 & $60^{\circ} \mathrm{C}$ & L19123 & (Kirisits et al, 1994; Shirai et al, 1989) \\
\hline iNOS & 30 & $63^{\circ} \mathrm{C}$ & U03699 & (Feinstein et al, 1996; Galea et al, 1994 \\
\hline
\end{tabular}

\footnotetext{
${ }^{1}$ This was the sequence of the probe used to detect GAPDH sequences following RT-PCR, however it should be noted that this sequence includes two mismatched nucleotides as compared to the original RNA sequence. The correct sequence should read CTAAGCAGTTGGTGGTGCA.
} 
loading buffer were added to each well in a $1.5 \%$ agarose gel and electrophoresed at $90 \mathrm{~V}$ for $60 \mathrm{~min}$ in $1 \times$ Tris buffer. After electrophoresis, the gels were denatured, neutralized and transferred to Hybond $\mathrm{N}^{+}$membranes (Amersham Life Science, Arlington Heights, IL, USA) using $10 \times$ SSC by standard capillary Southern blotting techniques (Southern, 1975). DNA was then cross-linked to the membrane by exposure to UV light for $2 \mathrm{~min}$ and baked at $80^{\circ} \mathrm{C}$ in a vacuum oven. Subsequent visualization of specific DNA bands on the blots was conducted using fluorescein labeled-oligonucleotide probes complimentary to the PCR products and detected using the enhanced chemical luminescence technique $\left(\mathrm{ECL}^{\mathrm{TM}}\right.$ ) (Amersham LifeScience, Buckinghamshire, England). Light output was detected on Hyperfilm ${ }^{\mathrm{TM}}$ ECL $^{\mathrm{TM}}$ film (Amersham LifeScience, Buckinghamshire, England), that was then scanned into a digital image. Blots were quantified by obtaining pixel densities using Scion Image software for Windows (Scion Corporation, Frederick, MD, USA) and normalizing relative changes in gene expression of each treatment group at each time point to their matched untreated controls. GAPDH signals were consistent for all experimental treatment groups. It is important to note that this procedure only allows for relative quantitation and comparisons of relationships among treatment groups and does not provide direct comparisons with exact levels (i.e., units) of mRNA among treatment groups (Wynn et al, 1993).

\section{$T N F-\alpha$ immunoassay}

TNF- $\alpha$ protein in primary astrocyte cultures supernatant was measured using the Quantikine ${ }^{\mathbb{B}} \mathrm{M}$ rat TNF- $\alpha$ kit (R\&D Systems, Minneapolis, MN, USA) as per manufacturer's instructions. Briefly, astrocyte cultures plated at $10^{6}$ cells/well were infected with one of the molecularly cloned VEE strains at an MOI of 1.0 or treated with IFN $\gamma /$ LPS. Untreated astrocytes were used as a negative control. Supernatants were harvested from three independent wells for each treatment group at 2, 6, 12, 24, and $48 \mathrm{~h}$ p.i., and media replaced after each sampling. All samples were stored at $4^{\circ} \mathrm{C}$ and diluted $1: 2$ with the calibrator diluent before assaying to bring TNF- $\alpha$ levels within the range of the standards. Standards, controls, and samples were assayed in duplicate at a wavelength of $450 \mathrm{~nm}$ and $550 \mathrm{~nm}$ for wavelength correction. Optical density (O.D.) was determined as the change in O.D. between the two wavelengths and intensity of the color reaction product was quantitated on a microplate reader (ELx800, Biotek Instruments, Inc., Winooski, VT, USA) using Kineticalc software for Windows ${ }^{\circledR}$ (Version 1.5, Biotek Instruments, Inc., Winooski, VT, USA). A range of TNF- $\alpha$ dilutions was used to generate a standard curve to determine TNF- $\alpha$ concentrations in the sample supernatant.
Nitrite assay procedure

The amount of nitric oxide produced by astrocytes was determined by assaying its stable oxidation product, $\mathrm{NO}^{-}{ }_{2}$ (nitrite) (Green et al, 1982). Briefly, equal volumes $(100 \mu \mathrm{l})$ of sample and Griess reagent $(1 \%$ sulfanilamide, $0.1 \% \quad N$-1-naphthyethylenediamine dihydrochloride in $2.5 \% \mathrm{H}_{3} \mathrm{PO}_{4}$ ) (Sigma, St. Louis, MO, USA) were mixed in a 96well plate. The optical density of the color reaction product from three independent samples was measured at $540 \mathrm{~nm}$ with a microplater reader (ELx800, Biotek Instruments, Winooski, VT, USA). A range of sodium nitrite dilutions was used to generate a standard curve. Values were quantified using Kineticalc software for Windows ${ }^{\mathbb{B}}$ (Version 1.5, Biotek Instruments, Inc., Winooski, VT, USA).

\section{Statistical analysis}

Data were analyzed using the software program SPSS for Windows ${ }^{\odot}$, version 8.0. VEE growth curves (Figure 2) data were analyzed using separate analysis of variances (ANOVAs) at 6, 12, and $24 \mathrm{~h}$ p.i. to determine whether there were treatment group effects. Least Significant Difference (LSD) post hoc tests were used to compare differences among groups at these time points. Cell viability data (Figure 3) were analyzed using repeated-measures ANOVA with the within-subjects factor of time and between-subjects factor of treatment in order to determine whether treatment groups differed over time. Separate ANOVAs were then conducted at 24,48 , and $72 \mathrm{~h}$ to determine whether groups differed significantly at these time points. LSD post hoc tests were used to compare differences among groups at these time points. Gene expression data (Figures 5 and 6) were normalized based on controls and analyzed using ANOVAs at each time point with the factor of treatment in order to determine whether groups differed based on treatment. Dunnett's post hoc tests were used to determine which treatment groups differed significantly from controls. These data also were analyzed with ANOVAs performed on each treatment group with the factor of time in order to determine whether treatment effects differed depending on time point measured. Dunnett's post hoc tests were also used to determine which time points within a specific treatment group (i.e., groups measured at 6, 12, 24, and $48 \mathrm{~h}$ ) differed from the group measured at $2 \mathrm{~h}$. Assays to determine NO and TNF- $\alpha$ production (Figures 7 and 8) were analyzed using separate ANOVAs at $6,12,24$, and $48 \mathrm{~h}$ in order to determine treatment effect. LSD post hoc analyses were then used to determine statistical differences among treatment groups. ANOVAs were two-tailed with $P<0.05$, whereas post hoc tests were onetailed because directionality (e.g., increase in gene expression) had been predicted with $P<0.05$. 


\section{Acknowledgements}

The authors would like to express their appreciation to Martha Faraday (USUHS) for statistical consultation, Dr Stephen Stohlman (USC) for editorial advice, and Liz Aquillo and Sandy Parks (AFFRI) for their help in establishing the astrocyte cultures. This work was supported by the TriService Nursing Research Program (grant MDA-90598-Z-0020), the Uniformed Services University of the Health Sciences (grant RO73DA), the Henry

\section{References}

Adamson DC, Wildemann B, Sasaki M, Glass JD, McArthur JC, Christov VI, Dawson TM, Dawson VL (1996). Immunologic NO synthase: elevation in severe AIDS dementia and induction by HIV-1 gp41. Science 274: $1917-1921$.

Aksamit AJ, Sever JL, Major EO (1986). Progressive multifocal leukoencephalopathy: JC virus detection by in situ hybridization compared with immunohistochemistry. Neurology 36: 499-504.

Aubert C, Chamorro M, Brahic M (1987). Identification of Theiler's virus infected cells in the central nervous system of the mouse during demyelinating disease. Microb Pathog 3: 319-326.

Banati RB, Gehrmann J, Schubert P, Kreutzberg GW (1993). Cytotoxicity of microglia. Glia 7: 111-118.

Bechmann I, Nitsch R (1997). Astrocytes and microglial cells incorporate degenerating fibers following entorhinal lesion: a light, confocal, and electron microscopical study using a phagocytosis-dependent labeling technique. Glia 20: 145-154.

Benveniste EN (1992). Inflammatory cytokines within the central nervous system: sources, function, and mechanism of action. Am J Physiol 263: C1-C16.

Brodie C, Weizman N, Katzoff A, Lustig S, Kobiler D (1997). Astrocyte activation by Sindbis virus: expression of GFAP, cytokines and adhesion molecules. Glia 19: $275-285$.

Carbone KM, Moench TR, Lipkin WI (1991). Borna disease virus replicates in astrocytes, Schwann cells and ependymal cells in persistently infected rats: location of viral genomic and messenger RNAs by in situ hybridization. J Neuropathol Exp Neurol 50: $205-214$.

Chao CC, $\mathrm{Hu} \mathrm{S}$, Sheng WS, Bu D, Bukrinsky MI, Peterson PK (1996). Cytokine-stimulated astrocytes damage human neurons via a nitric oxide mechanism. Glia 16: $276-284$.

Charles PC, Walters E, Margolis F, Johnston RE (1995). Mechanism of neuroinvasion of Venezuelan equine encephalitis virus in the mouse. Virology 208: 662671.

Chomczynski P, Sacchi N (1987). Single-step method of RNA isolation by acid guanidinium thiocyanatephenol-chloroform extraction. Anal Biochem 162: $156-159$.

Chung IY, Benveniste EN (1990). Tumor necrosis factoralpha production by astrocytes. Induction by lipopolysaccharide, IFN-gamma, and IL-1 beta. J Immunol 144: $2999-3007$.
Jackson Foundation for the Advancement of Military Medicine (grant 0006-731-6793), and the Armed Forces Radiobiology Research Institute (work unit 09501). All studies were carried out in accordance with the principles and procedures of the National Research Council Guide for the Care and Use or Laboratory Animals. The opinions or assertions contained herein are those of the authors and are not to be construed as official or reflecting the views of the Department of Defense or the United States Army.

Clatterbuck RE, Price DL, Koliatsos VE (1996). Ciliary neurotrophic factor stimulates the expression of glial fibrillary acidic protein by brain astrocytes in vivo. $J$ Comp Neurol 369: 543-551.

Davis NL, Powell N, Greenwald GF, Willis LV, Johnson BJ, Smith JF, Johnston RE (1991). Attenuating mutations in the E2 glycoprotein gene of Venezuelan equine encephalitis virus: construction of single and multiple mutants in a full-length cDNA clone. Virology 183: 20-31.

de la Monte S, Castro F, Bonilla NJ, Gaskin de Urdaneta A, Hutchins GM (1985). The systemic pathology of Venezuelan equine encephalitis virus infection in humans. Am J Trop Med Hyg 34: 194-202.

Dugan LL, Choi DW (1994). Excitotoxicity, free radicals, and cell membrane changes. Ann Neurol 35: S17S21.

Feinstein DL, Galea E, Aquino DA, Li GC, Xu H, Reis DJ (1996). Heat shock protein 70 suppresses astroglialinducible nitric-oxide synthase expression by decreasing NFkappaB activation. J Biol Chem 271: 1772417732 .

Fisher SN, Kim YU, Shin ML (1994). Tyrosine kinase activation by Newcastle disease virus is required for TNF-alpha gene induction in astrocytes. J Immunol 153: $3210-3217$.

Galea E, Reis DJ, Feinstein DL (1994). Cloning and expression of inducible nitric oxide synthase from rat astrocytes. J Neurosci Res 37: 406-414.

Gray CW, Patel AJ (1992). Characterization of a neurotrophic factor produced by cultured astrocytes involved in the regulation of subcortical cholinergic neurons. Brain Res 574: 257-265.

Green LC, Wagner DA, Glogowski J, Skipper PL, Wishnok JS, Tannenbaum SR (1982). Analysis of nitrate, nitrite, and [15N]nitrate in biological fluids. Annal Biochem 126: $131-138$.

Grieder FB, Davis BK, Zhou XD, Chen SJ, Finkelman FD, Gause WC (1997). Kinetics of cytokine expression and regulation of host protection following infection with molecularly cloned Venezuelan equine encephalitis virus. Virology 233: $302-312$.

Grieder FB, Davis NL, Aronson JF, Charles PC, Sellon DC, Suzuki K, Johnston RE (1995). Specific restrictions in the progression of Venezuelan equine encephalitis virus-induced disease resulting from single amino acid changes in the glycoproteins. Virology 206: 994-1006. 
Grieder FB, Nguyen HT (1996). Virulent and attenuated mutant Venezuelan equine encephalitis virus show marked differences in replication in infection in murine macrophages. Microb Pathog 21: 85-95.

Jackson A, Sen Gupta S, Smith J (1991). Pathogenesis of Venezuelan equine encephalitis virus infection in mice and hamsters. Vet Pathol 28: 410-418.

Jackson AC, Rossiter JP (1997). Apoptotic cell death is an important cause of neuronal injury in experimental Venezuelan equine encephalitis virus infection of mice. Acta Neuropathol (Berl) 93: 349-353.

Janzer RC, Raff MC (1987). Astrocytes induce blood-brain barrier properties in endothelial cells. Nature 325: $253-257$.

Johnson D, Grieder FB, Hearne C, Van Campen H (1997). Morphologic observation of RAW264.7 cells infected with attenuated and virulent VEE using electron microscopy. Proc Am Soc Microbiol Abstract.

Juliano SL, Palmer SL, Sonty RV, Noctor S, Hill GF 2nd (1996). Development of local connections in ferret somatosensory cortex. J Comp Neurol 37: 259-277.

Keyser DO, Pellmar TC (1994). Synaptic transmission in the hippocampus: critical role for glial cells. Glia 10: $237-243$.

Kirisits MJ, Vardimon D, Kunz HW, Gill TJD (1994). Mapping of the TNFA locus in the rat. Immunogenetics 39: $59-60$.

Kissling RE, Chamberlain RW (1967). Venezuelan equine encephalitis. Adv Vet Sci 11: $65-84$.

Kreil TR, Eibl MM (1996). Nitric oxide and viral infection: NO antiviral activity against a flavivirus in vitro, and evidence for contribution to pathogenesis in experimental infection in vivo. Virology 219: $304-$ 306.

Le Page C, Sanceau J, Drapier JC, Wietzerbin J (1996). Differential expression of inducible NO synthase in two murine macrophage cell lines. Immunology 89: $274-280$

Lieberman AP, Pitha PM, Shin HS, Shin ML (1989). Production of tumor necrosis factor and other cytokines by astrocytes stimulated with lipopolysaccharide or a neurotropic virus. Proc Natl Acad Sci USA 86: $6348-6352$.

Lieberman AP, Pitha PM, Shin ML (1990). Protein kinase regulates tumor necrosis factor mRNA stability in virus-stimulated astrocytes. I Exp Med 172: 989-992.

Lin YL, Huang YL, Ma SH, Yeh CT, Chiou SY, Chen LK, Liao CL (1997). Inhibition of Japanese encephalitis virus infection by nitric oxide: antiviral effect of nitric oxide on RNA virus replication. J Virol 71: 52275235.

Lowenstein CJ, Alley EW, Raval P, Snowman AM, Snyder SH, Russell SW, Murphy WJ (1993). Macrophage nitric oxide synthase gene: two upstream regions mediate induction by interferon gamma and lipopolysaccharide. Proc Natl Acad Sci USA 90: 9730-9734.

Marrero H, Orkand RK (1996). Nerve impulses increase glial intercellular permeability. Glia 16: 285-289.

McCarthy KD, de Vellis J (1980). Preparation of separate astroglial and oligodendroglial cell cultures from rat cerebral tissue. J Cell Biol 85: 890-902.
McIntire FC, Sievert HW, Barlow GH, Finley RA, Lee AY (1967). Chemical, physical, biological properties of a lipopolysaccharide from Escherichia coli K-235. Biochemistry 6: $2363-2372$.

Mendez E, Kawanishi T, Clemens K, Haruhiko S, Soldan SS, Calabresi P, Brady J, Jacobson S (1997). AstrocyteSpecific Expression of Human T-Cell Lymphotropic Virus Type 1 (HTLV-1) Tax: Induction of Tumor Necrosis Factor Alpha and Susceptibility to Lysis by CD8+ HTLV-1-Specific Cytotoxic Cells. J Virol 71: $9143-9149$

MMWR (1995). Venezuelan equine encephalitis Colombia, 1995. MMWR Morb Mortal Wkly Rep 44: 721724.

Molina-Holgado F, Lledo A, Guaza C (1997). Anandamide suppresses nitric oxide and TNF-alpha responses to Theiler's virus or endotoxin in astrocytes. Neuroreport 8: 1929-1933.

Mucke L, Eddleston M (1993). Astrocytes in infectious and immune-mediated diseases of the central nervous system. Faseb J 7: 1226-1232.

Muller HW, Beckh S, Seifert W (1984). Neurotrophic factor for central neurons. Proc Natl Acad Sci USA 81: $1248-1252$.

Neumann H, Boucraut J, Hahnel C, Misgeld T, Wekerle $H$ (1996). Neuronal control of MHC class II inducibility in rat astrocytes and microglia. Eur J Neurosci 8: $2582-2590$.

Nikcevich KM, Gordon KB, Tan L, Hurst SD, Kroepfl JF, Gardinier M, Barrett TA, Miller SD (1997). IFNgamma-activated primary murine astrocytes express B7 costimulatory molecules and prime naive antigenspecific T cells. J Immunol 158: 614-621.

Orkland RK, Opava SC (1994). Glial function in the homeostasis of the neuronal microenvironment. News Physiological Sciences 9: 265-267.

Rothwell NJ, Strijbos PJ (1995). Cytokines in neurodegeneration and repair. Int J Dev Neurosci 13: 179185.

Rus HG, Kim LM, Niculescu FI, Shin ML (1992). Induction of C3 expression in astrocytes is regulated by cytokines and Newcastle disease virus. J Immunol 148: $928-933$.

Scherer WF, Ellsworth CA, Ventura AK (1971). Studies of viral virulence. II. Growth and adsorption curves of virulent and attenuated strains of Venezuelan encephalitis virus in cultured cells. Am J Pathol 62: $211-$ 219.

Schmalenbach C, Muller HW (1993). Astroglia-neuron interactions that promote long-term neuronal survival. J Chem Neuroanat 6: 229-237.

Shirai T, Shimitzu N, Horiguchi S, Hirataka I (1989). Cloning and Expression in Eschreichia coli of the Gene for Rat Tumor Necrosis Factor. Agric Biol Chem 53: $1733-1736$.

Southern EM (1975). Detection of specific sequences among DNA fragments separated by gel electrophoresis. J Mol Biol 98: 503-517.

Stowring L, Haase AT, Petursson G, Georgsson G, Palsson P, Lutley R, Roos R, Szuchet S (1985). Detection of visna virus antigens and RNA in glial cells in foci of demyelination. Virology 141: 311-318. 
Suri NK, Banerjee K (1995). Growth and cytopathic effect of Japanese encephalitis virus in astrocyte-enriched cell cultures from neonatal mouse brains. Acta Virol 39: $143-148$.

Talley AK, Dewhurst S, Perry SW, Dollard SC, Gummuluru S, Fine SM, New D, Epstein LG, Gendelman HE, Gelbard HA (1995). Tumor necrosis factor alphainduced apoptosis in human neuronal cells: protection by the antioxidant $\mathrm{N}$-acetylcysteine and the genes blc-2 and crmA. Mol Cell Biol 15: 2359-2366.

Tornatore C, Chandra R, Berger JR, Major EO (1994). HIV-1 infection of subcortical astrocytes in the pediatric central nervous system. Neurology 44: $481-487$.

Tso JY, Sun XH, Kao TH, Reece KS, Wu R (1985). Isolation and characterization of rat and human glyceraldehyde-3-phosphate dehydrogenase cDNAs: genomic complexity and molecular evolution of the gene. Nucleic Acids Res 13: 2485-2502.

Tucker PC, Griffin DE, Choi S, Bui N, Wesselingh S (1996). Inhibition of nitric oxide synthesis increases mortality in Sindbis virus encephalitis. J Virol 70: $3972-3977$.

Vernadakis A (1996). Glia-neuron intercommunications and synaptic plasticity. Prog Neurobiol 49: 185-214.

Waage A, Halstensen A, Shalaby R, Brandtzaeg P, Kierulf P, Espevik T. (1989). Local production of tumor necrosis factor alpha, interleukin 1, and interleukin 6 in meningococcal meningitis. Relation to the inflammatory response. J Exp Med 170: 1859-1867.
Wesselingh SL, Levine B, Fox RJ, Choi S, Griffin DE (1994). Intracerebral cytokine mRNA expression during fatal and nonfatal alphavirus encephalitis suggests a predominant type $2 \mathrm{~T}$ cell response. J Immunol 152: $1289-1297$.

Wilkin GP, Marriott DR, Cholewinski AJ (1990). Astrocyte heterogeneity [news]. Trends Neurosci 13: 4346.

Wynn TA, Eltoum I, Cheever AW, Lewis FA, Gause WC, Sher A (1993). Analysis of cytokine mRNA expression during primary granuloma formation induced by eggs of Schistosoma mansoni. J Immunol 151: 1430-1440.

Xie QW, Whisnant R, Nathan C (1993). Promoter of the mouse gene encoding calcium-independent nitric oxide synthase confers inducibility by interferon gamma and bacterial lipopolysaccharide. J Exp Med 177: $1779-1784$.

Yoshida K, Gage FH (1991). Fibroblast growth factors stimulate nerve growth factor synthesis and secretion by astrocytes. Brain Res 538: 118-126.

Yoshioka M, Bradley WG, Shapshak P, Nagano I, Stewart RV, Xin KQ, Srivastava AK, Nakamura S (1995). Role of immune activation and cytokine expression in HIV1 associated neurologic diseases. Adv Neuroimmunol 5: $335-358$. 